\title{
The Eco-Classroom Project: Fostering Student Participation Through Education for Sustainability
}

\author{
Susan J. Wake \\ Supervisor \\ Dr Chris Eames
}

Abstract

This thesis investigated learning and other outcomes in participants, particularly students (9-11 years), as a result of their involvement in an education for sustainability (EfS) co-design and build project at their primary school in New Zealand, within the Enviroschools Programme. The research focused on four areas that distinguished the project: sustainability learning as the issue, participatory practice as the method, design as the process, and community partnerships as the sphere of involvement. Each of these was considered in terms of its influence on learning that was either cognitively based (knowledge), psychomotor (skills) or affective (attitudes and values). This led to the set-up of a matrix to collect qualitative data that was gathered using a narrative inquiry method around participants' stories. This included focus groups with students who were part of the Ecobuilding Working Party, interviews with key adults from the school and the wider community, survey questionnaires to parents of the focus group students, plus classroom observations and analysis of visual diaries made by the teacher.

Findings revealed student learning occurred in all three learning domains. This included EfS learning (particularly related to architecture and the built environment), understanding a design and build process, and cross-disciplinary learning that included skills such as leadership, teamwork and public speaking. Adult participants also gained from their involvement in the project. A correlation was made between the set-up and execution of the eco-classroom project and the Danish concept of Action Competence. This was indicated through the authentic, relevant and democratic action-taking focus of the eco-classroom project, which is linked to learning transformations. Also in agreement with an action competence approach was the strong focus in the project on both individual and collective learning. This was due to the process-focused nature of the project, itself related to the learning mandate and commitment to a democratic process with students. The project ran for a number of years with annually changing groups of students, who all had different experiences. The teacher used 'peer education' and reflective tools to manage the changeover of students positively. This gave depth and breadth to learning and ensured the project was truly collaborative. The embedding of learning in the project within the New Zealand Curriculum provided evidence of the flexible and multidisciplinary nature of EfS. Finally, a number of key management aspects were identified by the findings as contributing significantly to learning in the project and these are discussed. 


\section{Key Publications Generated}

The following refereed publications have resulted from the research described in this dissertation:

Wake, S.J., \& Eames, C. (2013). Developing an 'Ecology of Learning' within a school sustainability co-design project with children in New Zealand. Local Environment. doi:10.1080/13549839.2012.748723)

\section{Citation and Digital Source for Thesis:}

Wake, S.J. (2010). The eco-classroom project: Fostering student participation through education for sustainability. Master of Education unpublished thesis, The University of Waikato, Hamilton. Retrieved from http://hdl.handle.net/10289/5298

\section{Author Biography}

Susan Wake lectures in the Department of Landscape Architecture at Unitec Institute of Technology, Auckland. She has had a long interest in children and youth environments, especially with a participation and design focus. This led to her Masters in Education thesis emphasising environmental sustainability and children's participation and learning within a design project. She has published and presented in various forums and is currently teaching a course in designing children's environments. 